\title{
ОБЗОРЫ
}

УДК 624.195

ТЕОРИЯ И ПРАКТИКА КОНСТРУИРОВАНИЯ ДЕФОРМАЦИОННЫХ ШВОВ В ТРАНСПОРТНЫХ ТОННЕЛЯХ

\author{
${ }^{1}$ Гоппе В.Р., ${ }^{2}$ Вохмин С.А., ${ }^{2}$ Урбаев Д.А.
}

${ }^{1}$ ФГАОУ ВО «Российский университет транспорта», Москва, е-таil: vrhoppe@mail.ru; ${ }^{2}$ ФГАОУ ВО «Сибирский федеральный университет», Красноярск, е-таil: urbaev2011@mail.ru

В настоящей статье приведены воздействия, на которые рассчитываются тоннельные конструкции. Также описываются требования к ним в связи с уникальностью и повышенной ответственностью транспортных тоннелей. Обозначены следующие принципы конструирования деформационных швов в транспортных тоннелях: заложение в конструкцию шва обоснованной и достаточной его ширины, применение материалов шва с достаточной амплитудой деформации на сжатие и растяжение, учёт объемных деформаций самого транспортного сооружения, учёт изменчивости горно-геологических условий по длине сооружения, обеспечение эксплуатационной надёжности конструкций швов путём разработки и соблюдения регламентов производственных процессов. Обозначена проблема недостаточной защиты в конструкции традиционного деформационного шва от проникновения через него в тоннель грунтовых вод. Рассмотрены современные гидроизоляционные материалы для применения в конструкциях швов. Представлено сочетание неблагоприятных факторов, учёт которых позволяет рассчитать ширину деформационного шва. Приведена методика определения расчётного расстояния между антисейсмическими швами в монолитной железобетонной обделке и обоснована корректировка данного параметра с учётом технологии производства работ по бетонированию. Предложены принципиальные конструктивные решения для деформационных швов в конструкциях монолитных и сборных тоннельных обделок. Обозначены условия, при которых применение деформационных швов в сборной высокоточной тоннельной обделке нецелесообразно. Приведены факторы, от которых зависит количество и конструкция деформационных швов при их применении в сборной высокоточной тоннельной обделке. Представлены конструктивные и технологические особенности расстановки деформационных швов в обделке протяженных тоннелей с учетом температурных факторов. В выводе подчёркнута важная роль деформационных швов как элемента тоннельной конструкции, также обозначена недостаточная освещенность рассматриваемого вопроса в технической и нормативной литературе.

Ключевые слова: деформационный шов, транспортный тоннель, надёжность, продольная деформация, тоннельная обделка, горное давление, дорожное покрытие

\section{PRINCIPLES FOR THE DESIGN OF DEFORMATION SEAMS IN THE TRANSPORT TUNNELS}

${ }^{1}$ Goppe V.R., ${ }^{2}$ Vokhmin S.A., ${ }^{2}$ Urbaev D.A.

${ }^{1}$ Russian University of transport, Moscow, e-mail: vrhoppe@mail.ru;

${ }^{2}$ Siberian Federal University, Krasnoyarsk, e-mail: urbaev2011@mail.ru

This article shows the effects on which tunnel structures are calculated. Requirements to them due to uniqueness of increased responsibility of transport tunnels are also described. The following principles of construction of deformation seams in transport tunnels are indicated: laying in the structure of the seam of reasonable and sufficient width, application of the materials of the seam with a sufficient amplitude of deformation for compression and tension, taking into account volumetric deformations of the transport tunnel itself, taking into account variability of mining and geological conditions along the length of the tunnel, ensuring operational reliability of the structures of the seams by means of development and compliance with the regulations of production percentages. For reliable operation within the limits of the required life, some structural and technological solutions are proposed for the arrangement of deformation seams in transport tunnels, as to the most important and responsible elements of the tunnel structure. Denotes problem of insufficient protection of the traditional design of the deformation seams from penetrating there through in the tunnel groundwater.The modern waterproofing materials for use in seams constructions. The structure of the traditional deformation seam is shown, the problem of insufficient protection against penetration of groundwater into the tunnel through it is indicated. A combination of adverse factors is presented, which take into account allows calculating the width of the deformation seam. The technique of determining the calculated distance between the antiseismic seams in the lining and a monolithic reinforced concrete substantiated this adjustment parameter in view of production technology concreting works. Principal design solutions are proposed for deformation seams in structures of monolithic and prefabricated tunnel support. The conditions under which the use of deformation seams in a highprecision tunnel support is impractical are indicated. The factors on which the number and design of deformation seams during their application in a high-precision tunnel support are dependent are given. The design and technological features of the arrangement of deformation joints in the enclosure of long tunnels are presented taking into account temperature factors. The output underlined the important role of the deformation seams as a structural element of the tunnel, as indicated by the lack of brightness of the issue at technical and regulatory literature.

Keywords: deformation seams, transport tunnel, reliability, longitudinal strain, tunnel support, rock pressure, road surface

Конструкции обделок тоннелей должны быть запроектированы и сооружены таким образом, чтобы они обладали достаточной надежностью при возведении и эксплуатации с учетом при необходимости также и особых динамических и термических воздействий. 
Основным свойством, определяющим надежность строительных конструкций и сооружений в целом, является безотказность их работы, способность сохранять заданные эксплуатационные качества в течение определенного срока службы.

Транспортные тоннели в большинстве, в соответствии с положениями нормативных документов, относятся к сооружениям повышенного уровня ответственности. Это требует, для обеспечения их надежности и долговечности, не только безусловного выполнения обязательных для применения норм проектирования, строительства и содержания указанных тоннелей, но и специальных подходов к отдельным (особо ответственным) элементам конструкций тоннельных обделок.

Действующие нормативные документы, а также опыт проектирования и сооружения подземных объектов требует устраивать деформационные швы, отсекающие определенные участки сооружения друг от друга.

В нормативных документах и технической литературе по подземному строительству деформационным швам - ответственнейшим элементам тоннельного сооружения - уделено неоправданно мало внимания.

\section{Деформационные ивы в монолитной железобетонной тоннельной обделке}

Тоннельные обделки - это статически неопределимые системы. Поэтому при изменении температуры конструкции, при усадке бетона конструкции, при неравномерной осадке основания, при несимметричном отпоре породы по бокам выработки тоннеля в конструкции обделки возникают внутренние усилия, которые могут приводить к трещинообразованию или разрушению частей конструкции - при этом может быть нарушена водонепроницаемость и несущая способность конструкции тоннельной обделки.

В конструкции тоннельной обделки деформационный шов - это определенной ширины поперечный перпендикулярный продольной оси тоннеля разрез конструкции его обделки. Шов разделяет тоннельную обделку на отдельные блоки (секции). В этих отдельных блоках деформации практически не зависят от деформаций соседнего блока (секции) - обделка в отдельных блоках может деформироваться в разной степени и без разрушений.

Деформационные швы обеспечивают адаптацию работы тоннельной обделки в системе «крепь-массив» при воздействии стохастических факторов, способных вызвать опасные внутренние усилия, которые могут снизить несущую способность конструкций.

Железобетонные конструкции с изменением температуры деформируются укорачиваются либо удлиняются, а вследствие усадки бетона укорачиваются. При неравномерной осадке основания части конструкций стремятся сместиться в разных направлениях.

Главные функции конструкции деформационных швов: они должны быть водонепроницаемыми и способными работать без повреждений (оставаться водонепроницаемыми при смещении смежных участков (секций) тоннелей в различных направлениях: растяжение-сжатие, сдвиг, кручение).

Для этого разрабатываются и совершенствуются различные конструктивные элементы, позволяющие дополнять друг друга и взаимно страховать надежность всей конструкции деформационного шва.

Конструктивно герметизация деформационных швов в большинстве случаев обеспечивается вставками из упругих полимерных материалов.

Кроме того, могут дополнительно предусматриваться полимерные уплотнительные шнуры и гидрошпонки (рисунок) [1].

В процессе проектирования, строительства и содержания готового тоннельного сооружения в конструкциях деформационных швов в некоторых случаях допускаются ошибки и брак.

При проектировании это:

- заложенная в конструкцию недостаточная ширина шва (ширина поперечного разреза конструкции);

- применение для заполнения шва материалов с недостаточной амплитудой деформативности (растяжения-сжатия);

- не учёт объемных деформаций в сооружении (деформаций кручения, сдвига, «клавишного эффекта» и т.п.);

- не учёт при расстановке деформационных швов геологических аномалий и резких изменений физико-механических свойств горных пород по длине сооружения;

- отсутствие в проектной документации или неполнота требований к обеспечению эксплуатационной надежности конструкций (в частности, деформационных швов);

- и др.

При строительстве это [2]:

- нарушения и отклонения от проектных решений в части обеспечения проектной ширины деформационных швов; 


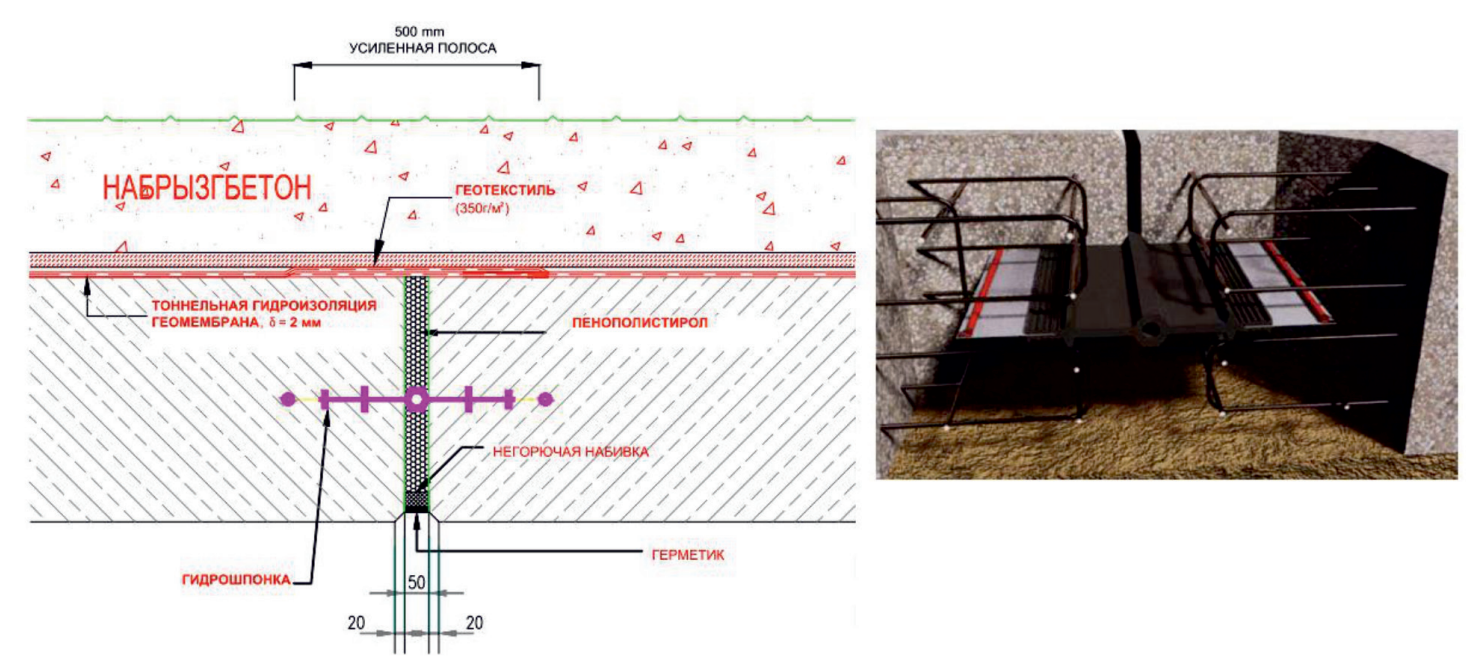

Вариант узла деформационного шва в монолитной ж.б. тоннельной обделке (справа вид расположения гидрошпонки)

- применение для заполнения деформационных швов материалов, не соответствующих проектным решениям;

- не учёт при расстановке деформационных швов реальных инженерно-геологических условий по длине сооружения в соответствии с исполнительной геологической съемкой (не учет аномалий и резких изменений физико-механических свойств горных пород, выявленных при строительстве);

- и др.

При содержании это:

- отсутствие или неполнота исполнительной документации тоннельного сооружения;

- ненадлежащее ведение мониторинга (инженерных систем и горно-экологического) тоннельного сооружения.

В таких случаях часто деформационные швы становятся местом, через которое внутрь тоннеля проникают грунтовые и пластовые воды, т.е. водонепроницаемость швов необходимым образом не обеспечивается [3-5].

Кроме того, неправильно сконструированные или некачественно выполненные деформационные швы могут способствовать возникновению в секциях тоннельной обделки дополнительных внутренних усилий, которые не учитывались в расчетах - что, в свою очередь, может привести к трещинообразованию в конструкции, нарушению водонепроницаемости тела тоннельной обделки, а в дальнейшем к потере несущей способности конструкции [6].

Для расчета ширины разреза тоннельной обделки деформационным швом необходимо учесть максимально неблагопри- ятное сочетание факторов, действующих одновременно и вызывающих деформации конструкции обделки [7].

Для определения расстояния между антисейсмическими швами $(L$, м) в монолитной ж.б. тоннельной обделке можно использовать формулу по [5]:

$$
L=\frac{\delta_{\text {сейсм }} c_{1} T_{0}}{4 \pi A},
$$

где $c_{1}$ - скорость продольных сейсмических волн в грунте, м/с; $T_{0}-$ преобладающий период сейсмических колебаний массива, определяемый в процессе изыскания, с; $A$ - возможная максимальная амплитуда колебаний массива, см, определяемая в процессе изысканий; $\delta_{\text {сейсм }}-$ допускаемое конструкцией шва продольное смещение смежных участков тоннеля относительно друг друга при расчетном сейсмическом воздействии, см.

Для снижения величины деформаций ползучести и усадки бетона могут быть применены различные подходы. Один из них - применение фибробетона при сооружении конструкции тоннельной обделки. Такое армирование применяется как в качестве дополнения к традиционному армированию конструкций стержневой арматурой, так и в качестве самостоятельного решения для тоннельных конструкций. Армирование несущих конструкций фиброй повышает морозостойкость и огнестойкость конструкции, трещиностойкость бетона конструкции, придает конструкции вязкость и стойкость от хрупкого разруше- 
ния. Другой подход - применение новой конструкции температурно-усадочного шва, позволяющей исключить применение деформационных швов [8].

Учет дополнительного наложения температурной деформации бетона также необходим в некоторых случаях. При этом значима величина максимального возможного перепада температур. Если такой перепад относительно невелик и вероятность землетрясения с максимальной магнитудой также невелика, то совместный их учет приведет к излишнему конструктивному запасу - ширина деформационного шва будет завышена [9].

С другой стороны, так как конструкция деформационного шва должна допускать взаимные продольные смещения смежных участков обделки при их деформациях без силового воздействия секций обделки друг на друга, фактическая ширина шва должна быть увеличена.

Из опыта расчетов этой величины ширина деформационного шва $\Delta_{\text {дш }}$ составляет 40-50 мм (рисунок).

Касательно конструкции антисейсмических деформационных швов следует отметить, что они должны обеспечивать независимую подвижность секций тоннельных обделок во всех направлениях: продольные, поперечные и вращательные перемещения [10-11]. Это необходимо, т.к. сейсмические волны (растяжения-сжатия и сдвига) практически могут воздействовать по любым направлениям [12-14].

\section{Деформачиионные швы в сборной высокоточной тоннельной обделке}

В настоящее время при сооружении тоннелей при помощи тоннелепроходческих щитовых комплексов особенно широко применяются сборные высокоточные железобетонные тоннельные обделки [15-17], применяются также на отдельных участках (в особо тяжелых инженерно-геологических условиях, а также на участках сопряжений тоннеля с вспомогательными притоннельными сооружениями) тюбинговые чугунные и стальные обделки.

Из практики проектирования таких тоннельных обделок известно, что устраивать в них деформационные швы целесообразно в следующих случаях [18-20]:

- в местах изменения жесткости конструкции тоннельных обделок, в местах примыкания к основному тоннелю притоннельных сооружений и т.п.) - т.е. на стыке железобетонной обделки с тюбинговой, на стыке тоннельной обделки с конструкцией притоннельного сооружения;

- в зонах возможных тектонических сдвигов окружающего тоннель массива;

- в зонах деформаций от неравномерного воздействия горного давления или в зонах локальных осадок основания тоннельного сооружения и других подобных явлений.

Расстановка равномерно вдоль тоннеля температурных и антисейсмических деформационных швов в случае применения сборных тоннельных обделок нецелесообразна - конструкция тоннельной обделки в данном случае обладает достаточной податливостью, чтобы воспринять деформации от соответствующих воздействий.

Таким образом, при проектировании тоннельных сооружений со сборными обделками расстановка и конструкция деформационных швов в каждом случае индивидуальна и зависит от инженерногеологических условий заложения сооружения, а также от компоновки сооружения.

Следует отметить, что в отечественной технической литературе по тоннелестроению до настоящего времени не освещалась тема индивидуального конструирования деформационных швов для транспортных тоннелей, сооружаемых при помощи тоннелепроходческих щитовых комплексов.

На наш взгляд, в этой области тоннелестроительной науки имеется пробел, который требует проработки (восполнения).

\section{Расстановка деформациионных швов в тоннельной обделке с учетом температурных факторов}

Правильно выполненные и технически обоснованным образом расположенные в тоннельном сооружении деформационные швы во многом обеспечивают его эксплуатационные качества, надежность и долговечность всего тоннельного сооружения [21-23].

В целом качественно спроектированная и качественно сооружённая тоннельная обделка должна быть сухой. Но если несущая конструкция обделки будет удовлетворять этому условию, а деформационные швы нет, то очень быстро эксплуатационные качества тоннеля будут резко снижены, резко возрастут затраты на содержание и текущий ремонт.

Целесообразно для каждого тоннельного сооружения применять ряд типовых конструкций деформационных швов, рассчитанных на разный тип смещений и на разную амплитуду смещений. 
Как уже указывалось выше, учет расчетных продольных температурных деформаций тоннельной обделки также необходим [24].

Целесообразно в период строительства фиксировать температурные показатели окружающей среды, температурные показатели твердеющего бетона конструкции обделки. Параметры очередного устанавливаемого деформационного шва необходимо назначать с учетом возможной разности температур тоннельной обделки в течение года [25]. Необходимо, таким образом, в процессе строительства иметь несколько типов деформационных швов для одного и того же тоннеля.

Известно, что для протяженных тоннелей характерна различная (непостоянная) амплитуда температур в течение года в зависимости от близости обделки к порталу или к вентиляционному стволу.

На входных (припортальных) участках тоннелей и на участках, смежных с вентиляционными стволами (это наиболее проблемные участки по температурным деформациям), конструкции деформационных швов должны быть особенно стойкими как к пониженным температурам, так и к повышенным, а также к внутридневным колебаниям температур, от положительных к отрицательным.

Следует также и при сооружении тоннелей при помощи тоннелепроходческих щитовых комплексов учитывать в период строительства температурные показатели окружающей среды, температурные показатели конструкции сборной обделки в момент ее монтажа.

В данном случае при проектировании необходимо определить точные параметры поперечной и продольной податливости сборной обделки и, с их учетом, определять необходимость установки деформационного шва в конструкцию обделки.

Параметры очередного устанавливаемого деформационного шва необходимо также назначать с учетом возможной разности температур тоннельной обделки в течение года. Необходимо, таким образом, в процессе строительства и здесь иметь несколько типов деформационных швов для одного и того же тоннеля.

\section{Выводы}

1. Правильно выполненные и технически обоснованным образом расположенные в тоннельном сооружении деформационные швы - это элементы в тоннельном сооруже- нии, которые обеспечивают нормальные условия его эксплуатации, безотказную работу и исправное состояние на протяжении жизненного цикла объекта (проектного срока службы сооружения).

2. В нормах, обязательных для применения при проектировании и строительстве тоннельных сооружений, необходимо предусмотреть дополнительные требования к конструкциям деформационных швов.

3. Индустриальное производство деформационных швов и их элементов, а также разработка специальных конструкций для подземных сооружений - это направление для организации новых специализированных производств и развития отрасли подземного строительства.

\section{Список литературы / References}

1. Гоппе В.Р. Деформационные швы в автодорожных тоннелях // Метро и тоннели. 2012. № 3. С. 30-34.

Goppe V.R. Deformation seams in road tunnels// Metro and tunnels. 2012. № 3. P. 30-34 (in Russian).

2. Рекомендации по применению конструкций деформационных швов с резиновыми компенсаторами при строительстве и ремонте пролетных строений автодорожных мостов и путепроводов / Гипродорнии. Сост. В.И. Шестериков. М.: ЦБНТИ Минавтодора РСФСР, 1986. 45 с.

Recommendations on the use of structures of expansion joints with rubber expansion joints in the construction and repair of spans of road bridges and overpasses / Giprodornii. Sost. V.I. Shesterikov. M.: TSBNTI Minavtodora RSFSR, 1986. 45 p. (in Russian).

3. Гоппе В.Р. Строительство тоннелей. Учебное пособие. М.: МИИТ, 2016. 437 c.

Goppe V.R. Construction of tunnels. Manual. M.: MIIT, 2016. 437 p. (in Russian).

4. ГОСТ P 54257-2010. Надежность строительных конструкций и оснований. Введ. 2011-09-01. М.: ИПК. Изд. стандартов, 2011. 18 с.

5. Смирнова Г.О. Нормативная документация и порядок применения новых строительных материалов в метрои тоннелестроении // Подземные горизонты. 2019. № 21. C. $12-15$.

Smirnova G.O. Regulatory documentation and procedure for application of new construction materials in metro- and tunnel construction // Podzemnyye gorizonty. 2019. № 21. P. 1215 (in Russian).

6. Конных А.А., Меркин В.Е., Кезин А.С. Тоннель с отрицательной в зимний период температурой воздуха в его внутренней части // Патент РФ № 2706496. Патентообладатель ПАО «Мостотрест». 2019. Бюл. № 32.

Konny A.A., Merkin V.E., Kezin A.S. Tunnel with negative air temperature in its inner part in winter // Patent of the Russian Federation № 2706496. Patent holder of PJSC Mostotrest. 2019. Bulletin No. 32 (in Russian).

7. Фролов Ю.С., Иванес Т.В. Механика подземных сооружений. СПб.: ПГУПС, 1993. 102 с.

Frolov Y.S., Ivanes T.V. Mechanics of underground structures. SPb.: PGUPS, 1993. 102 p. (in Russian).

8. Пассек В.В., Антонов Е.А., Меркин В.Е., Величко В.П., Иванова Н.М., Гиренко И.В. Температурно-усадочный шов // Патент РФ № 2299946. 2007. Бюл. № 15.

Passek V.V., Antonov E.A., Merkin V.E., Velichko V.P., Ivanov N.M., Girenko I.V. Temperature-shrinkage seam // Patent of the Russian Federation № 2299946. 2007. Bulletin No. 15 (in Russian). 
9. Методическое руководство по комплексному горноэкологическому мониторингу при строительстве и эксплуатации транспортных тоннелей. М.: УРАН ИПКОН РАН, НИПИИ «Ленметрогипротранс», 2009. 68 с.

Methodological guidelines for integrated mining and environmental monitoring during the construction and operation of transport tunnels. M.: URAN IPKON RAN, NIPII «Lenmetrogiprotrans», 2009. 68 p. (in Russian).

10. Тешаев У.Р., Хасанов Н.М., Абдужабаров А.Х Сейсмостойкость конструкций водопропускных сооружений и подземных переходов // Вестник гражданских инженеров. 2017. № 1 (60). С. 205-209.

Teshaev U.R., Khasanov N.M., Abduzhabarov A.H. Seismic resistance of water-passage structures and underground crossings // Vestnik grazhdanskikh inzhenerov. 2017. № 1 (60) P. 205-209 (in Russian).

11. СП 14.13330.2011. Актуализированная редакция СНиП II-7-81* Строительство в сейсмических районах Введ. 2011-05-20. М.: ФГУП ЦПП. [Электронный ресурс]. URL: http://docs.cntd.ru/document/1200084534 (дата обращения: 28.05.2020).

12. Yashiro K., Fachibara N., Kajima Y., Nonomura M. Asakura T. Model test on behavior of tunnels under deformation of the ground upon earthquake. Proceedings of tunnel engineering. 2007. JSCE (5). P. 63-71.

13. Руководство по расчёту и проектированию транспортных тоннелей для районов с повышенной сейсмичностью. М.: Министерство строительства и ЖКХ РФ, 2018. $165 \mathrm{c}$.

Guidance on the calculation and design of transport tunnels for areas with increased seismicity. M.: Ministerstvo stroitel'stva i ZHKKH RF, 2018. 165 p. (in Russian).

14. Розенвассер Г.Р., Петрук В.В., Букань А.П. Концепция защиты дренажно-коммуникационного тоннеля от влияния сейсмических воздействий // Метро и тоннели. 2003 № 3. C. $36-42$.

Rosenwasser, G.R., Petruk V.V., Bukan A.P., Concept of Protection of Drainage and Communication Tunnel from Seismic Impacts // Metro and tunnels. 2003. № 3. P. 36-42 (in Russian).

15. СП 120.13330.2012. Метрополитены. Актуализированная редакция СНиП 32-02-2003. М.: Минрегион, 2012. [Электронный pecypc]. URL: https://docinfo.ru/sp/sp120-13330-2012/ (дата обращения: 28.05.2020).

16. СП 122.13330.2012. Тоннели железнодорожные и автодорожные. Актуализированная редакция СНиП 32 04-97. М.: Минрегион, 2012. [Электронный ресурс]. URL: http://docs.cntd.ru/document/1200095544 (дата обращения: 28.05.2020).

17. Herrenknecht Tunnelling Systems [Electronic resource] URL: https:/www.herrenknecht.com/en/products/productdetail/ segment-production-systems (date of access: 14.05.2020).

18. Положение по проведению строительного контроля при строительстве, реконструкции, капитальном ремонте объектов капитального строительства. М.: ОАО «Научнотехнический центр «Промышленная безопасность», 2009. $19 \mathrm{c}$

Regulation on the construction control during construction, reconstruction, overhaul of capital construction facilities. M.: OAO «Nauchno-tekhnicheskiy tsentr «Promyshlennaya bezopasnost'», 2009. 19 p. (in Russian).
19. СП 34.13330.2012. Автомобильные дороги. Актуализированная редакция СНиП 2.05.02-85*. Введ. 2012-0630. М.: ФГУП ЦПП. [Электронный ресурс]. URL: http://docs. cntd.ru/document/1200095524 (дата обращения: 28.05.2020).

20. СП 63.13330.2012. Бетонные и железобетонные конструкции. Основные положения. Актуализированная редакция СНиП 52-01-2003. Введ. 2011-12-29. М.: ФГУП ЦПП. [Электронный ресурс]. URL: http://docs.cntd. ru/document/1200095246 (дата обращения: 28.05.2020).

21. Федеральный закон от 30.12.2009 г. № 384-Ф3 «Технический регламент о безопасности зданий и сооружений» [Электронный ресурc]. URL: http://www.consultant.ru/ cons/cgi/online.cgi?req $=$ doc $\&$ base $=$ LAW $\&$ n $=148719 \&$ fld $=$ $134 \& \mathrm{dst}=1000000001,0 \& \mathrm{rnd}=0.6528414365517419$ \# 07495292799192497 (дата обращения: 28.05.2020).

Federal Law of December 30, 2009 No. 384-Ф3 «Technical Regulations on the Safety ofBuildings and Structures» [Electronic resource]. URL: http://www.consultant.ru/cons/cgi/online.cgi ?req $=$ doc $\&$ base $=$ LAW \&n $=148719 \&$ fld $=134 \&$ dst $=100000000$ $1,0 \&$ rnd $=0.6528414365517419 \# 07495292799192497$ (date of access: 28.05.2020) (in Russian).

22. Постановление Правительства РФ от 21.06.2010 г. № 468 «О порядке проведения строительного контроля при осуществлении строительства, реконструкции и капитального ремонта объектов капитального строительства». [Электронный ресурс]. URL: http://base.garant.ru/12176727/ (дата обращения: 28.05.2020).

Decree of the Government of the Russian Federation of June 21, 2010 No. 468 «On the Procedure for Conducting Construction Control during the Construction, Reconstruction and Overhaul of Capital Construction Facilities». [Electronic resource]. URL: http://base.garant.ru/12176727/ (date of access: 28.05.2020) (in Russian).

23. Постановление Правительства РФ от 26.12.2014 г. № 1521 «Об утверждении перечня национальных стандартов и сводов правил (частей таких стандартов и сводов правил), в результате применения которых на обязательной основе обеспечивается соблюдение требований Федерального закона «Технический регламент о безопасности зданий и сооружений» [Электронный pecypc]. URL: https://www. minstroyrf.ru/upload/iblock/b10/perechen-1521.pdf (дата обращения: 28.05.2020).

Decree of the Government of the Russian Federation of December 26, 2014 No. 1521 «On approval of the list of national standards and codes of rules (parts of such standards and codes of rules), the application of which on a mandatory basis ensures compliance with the requirements of the Federal Law» Technical Regulation on the Safety of Buildings and constructions». [Electronic resource]. URL: https://www.minstroyrf.ru/upload/ iblock/b10/perechen-1521.pdf (date of access: 28.05.2020) (in Russian).

24. Vokhmin S.A., Teshaev U.R., Padamata S.K., Trebush Y.P., Khasanov N.M. Assessment of defectsin mountain roadway tunnel due to various and operational factors - Istiqlol (Republic of Tajikistan). Of the national academy of sciences of the republic of Kazakhstan series of geology and technical sciences. 2018. vol. 5. no. 431. P. 76-85. DOI: 10.32014/2018.2518-170X.11.

25. СП 131.13330.2012 Строительная климатология. Актуализированная редакция СНиП 23-01-99*. Введ. 2013-0101. М.: ФГУП ЦПП. [Электронный ресурс]. URL: http://docs. cntd.ru/document/1200095546 (дата обращения: 28.05.2020). 